\title{
Chronic Adolescent Exposure to $\Delta$-9-Tetrahydrocannabinol in COMT Mutant Mice: Impact on Psychosis-Related and Other Phenotypes
}

\author{
Colm MP O'Tuathaigh*,', Magdalena Hryniewiecka², Aine Behan², Orna Tighe', Catherine Coughlan', \\ Lieve Desbonnet', Mary Cannon ${ }^{2}$, Maria Karayiorgou ${ }^{3}$, Joseph A Gogos ${ }^{4}$, David R Cotter ${ }^{2}$ and \\ John L Waddington' \\ 'Molecular and Cellular Therapeutics, Royal College of Surgeons in Ireland, Dublin, Ireland; ${ }^{2}$ Department of Psychiatry, Royal College of Surgeons \\ in Ireland, Dublin, Ireland; ${ }^{3}$ Department of Psychiatry and Genetics \& Development, Columbia University, New York, NY, USA; ${ }^{4}$ Department of \\ Physiology and Cellular Biophysics and Department of Neuroscience, Columbia University, New York, NY, USA
}

\begin{abstract}
Cannabis use confers a two-fold increase in the risk for psychosis, with adolescent use conferring even greater risk. A high-low activity catechol-O-methyltransferase (COMT) polymorphism may modulate the effects of adolescent $\Delta$-9-tetrahydrocannabinol (THC) exposure on the risk for adult psychosis. Mice with knockout of the COMT gene were treated chronically with THC (4.0 and $8.0 \mathrm{mg} / \mathrm{kg}$ over 20 days) during either adolescence (postnatal days (PDs) 32-52) or adulthood (PDs 70-90). The effects of THC exposure were then assessed in adulthood across behavioral phenotypes relevant for psychosis: exploratory activity, spatial working memory (spontaneous and delayed alternation), object recognition memory, social interaction (sociability and social novelty preference), and anxiety (elevated plus maze). Adolescent THC administration induced a larger increase in exploratory activity, greater impairment in spatial working memory, and a stronger anti-anxiety effect in COMT knockouts than in wild types, primarily among males. No such effects of selective adolescent THC administration were evident for other behaviors. Both object recognition memory and social novelty preference were disrupted by either adolescent or adult THC administration, independent of genotype. The COMT genotype exerts specific modulation of responsivity to chronic THC administration during adolescence in terms of exploratory activity, spatial working memory, and anxiety. These findings illuminate the interaction between genes and adverse environmental exposures over a particular stage of development in the expression of the psychosis phenotype.

Neuropsychopharmacology (2010) 35, 2262-2273; doi:I0.1038/npp.20 I0.100; published online I4 July 2010
\end{abstract}

Keywords: animal model; adolescence; psychosis; COMT; $\Delta$-9-tetrahydrocannabinol; gene $\times$ environment interaction

\section{INTRODUCTION}

Cannabis consumption has been associated with a doubling of the risk for schizophrenia (Arseneault et al, 2004; Henquet et al, 2005; Moore et al, 2007) and with a negative impact on the expression and course of schizophrenia (Martinez-Arevalo et al, 1994; Linszen et al, 1994). Systemic, acute administration of $\Delta$-9-tetrahydrocannabinol (THC), the psychoactive component of cannabis, has been shown to transiently induce positive symptoms, negative symptoms, and cognitive impairment, including deficits in working memory and executive function, in healthy subjects (D'Souza et al, 2004, 2009; Stefanis et al, 2004; Morrison et al, 2009) and to exacerbate these features in patients with

*Correspondence: Dr CMP O'Tuathaigh, Department of Molecular and Cellular Therapeutics, Royal College of Surgeons in Ireland, $123 \mathrm{St}$ Stephen's Green, Dublin 2, Ireland, Tel: + 3531402 2377, Fax: + 35 31 402 2453, E-mail: cotuathaigh@rcsi.ie

Received 29 March 20 I0; revised 6 June 20 I0; accepted I 3 June 2010 schizophrenia (D'Souza et al, 2005). Although cannabinoids produce a variable pattern of schizophrenia-like symptoms in healthy subjects, it has been proposed that the developmental timing of cannabis exposure and genetic factors may interact to modulate the effects of cannabis on the risk for psychosis (D'Souza et al, 2009).

It seems that the risk for psychosis is greater in those subjects who use cannabis in adolescence (Arseneault $e t$ al, 2002; Ashton, 2003). Adolescence may be a stage of particular vulnerability to the effects of THC, as cannabinoid receptors have been shown to mature slowly, reaching maximal levels during adolescence that may reduce subsequently because of postadolescent pruning, in a manner similar to that described for dopamine (DA) receptors (Rodriguez de Fonseca et al, 1993; McLaughlin et al, 1994; Belue et al, 1995; Seeman, 1999). Chronic THC administration in adolescent rats has been shown to induce persistent changes in cognitive and emotional processes in adulthood (Schneider and Koch, 2003; Cha et al, 2006, 2007; Rubino et al, 2009). 
The catechol-O-methyltransferase (COMT) gene, located on chromosome 22q11 (a region implicated in schizophrenia), encodes the COMT enzyme, which is involved in the degradation of DA, particularly in the prefrontal cortex (PFC). The human COMT gene contains a common functional polymorphism (valine (Val) substitution for methionine (Met)) at the 158/108 locus, with the Met allele resulting in a four-fold reduction in enzymatic activity (Tunbridge et al, 2006). COMT Val108Met allelic variation has been associated with differential performance on tasks measuring PFC-mediated cognition, including working memory and executive function (Egan et al, 2001; Tunbridge et al, 2006). Mutant mice bearing targeted mutations of COMT provide some insights into the role of COMT in several aspects of behavior, including PFC-mediated cognition (Gogos et al, 1998; Desbonnet et al, 2009; Kirby et al, 2010). Male COMT knockout (KO) mutants show improvement in spatial working memory (Babovic et al, 2008; Papaleo et al, 2008), whereas, conversely, a transgenic COMT mutant involving overexpression of the human COMT-VAL polymorphism shows deficits in attentional set shifting, recognition memory, and working memory performance; low-dose amphetamine restored recognition memory, confirming DAergic involvement and providing further support for an inverted U-shaped relationship between cognitive function and cortical DAergic activity (Seamans and Yang, 2004; Tunbridge et al, 2006).

A longitudinal birth cohort study showed that cannabis use was most likely to be followed by psychosis among those who used cannabis during adolescence and were homozygous for the COMT Val108Met allele (Caspi et al, 2005). Carriers of the Val allele are also more likely to show THC-induced psychotomimetic and amnestic effects than Met carriers, although this was conditional on increased 'psychosis proneness' as measured by psychometric tests (Henquet et al, 2006). Although the underlying mechanism is unknown, these gene $\times$ environment findings have provided new clues to how adolescent cannabis use may lead to psychosis. It is proposed that exploration of a COMT-linked component underlying the induction of psychosis-relevant phenotypes after chronic adolescent $v s$ adult THC treatment has the potential to provide insight into the lasting psychotomimetic effects of chronic cannabis use. The aim of this study was to investigate psychosisrelevant behavioral phenotypes in adult COMT KO mice after chronic adolescent $v s$ adult THC exposure. It was hypothesized that knockout of the COMT gene would preferentially modify the long-term effects of chronic adolescent $v s$ adult THC exposure on the expression of various psychosis-relevant cognitive, social, and anxietyrelated behaviors during adulthood.

\section{METHODS}

\section{Animals}

Mice containing the mutated COMT allele were generated at the Rockefeller University (New York, NY, USA) and backcrossed to C57BL6 mice for 10 generations (Gogos et al, 1998); breeding and genotyping at the Royal College of Surgeons in Ireland were performed as described previously (Babovic et al, 2007, 2008). After weaning on postnatal day
(PD) 21, pups from litters of the same generation were housed in groups of three to five per cage and maintained at $21 \pm 1{ }^{\circ} \mathrm{C}$ on a 12 -h light-dark cycle $(0700 \mathrm{~h}$ on; $1900 \mathrm{~h}$ off), with ad libitum access to food and water. Males and females of wild-type (WT), COMT heterozygous (HET), and COMT KO genotypes, 8-15 mice per sex, treatment and genotype, were treated over 20 consecutive days, either PDs 32-52, corresponding to adolescence or PDs 70-90, corresponding to adulthood. These studies were approved by the Research Ethics Committee of the Royal College of Surgeons in Ireland. They were conducted under license from the Department of Health and Children, in accordance with the Irish legislation and the European Communities Council Directive 86/609/EEC for the care and use of experimental animals, and from the Environmental Protection Agency in relation to the contained use of genetically modified organisms. All efforts were made to minimize the number of animals used and their suffering.

\section{Drugs}

THC (Sigma-Aldrich, St Louis, MO, USA) was dissolved in saline:cremaphor:ethanol $(18: 1: 1)$ for subcutaneous (s.c.) injection at 4.0 and $8.0 \mathrm{mg} / \mathrm{kg}$ (s.c., $4 \mathrm{ml} / \mathrm{kg}$ ); these doses were selected on the basis of previous studies of chronic THC effects in rodents (Quinn et al, 2008; Rubino et al, 2009). Vehicle controls received identical injection of the final saline:cremaphor:ethanol solution. The ethanol concentration in the THC solution results in ethanol doses of approximately $0.05-0.15 \mathrm{~g} / \mathrm{kg}$; this vehicle solution has customarily been used by many laboratories for the solubilization of cannabinoids, and does not induce any significant behavioral effects (Rubino et al, 2009). After both adolescent (PDs 32-52) and adult (PDs 70-90) treatments, there was an interval of 21 days before behavioral testing, to exclude withdrawal effects. Initially, 10-15 mice per group (genotype/treatment/sex) were examined for exploratory activity; thereafter, a randomly selected subset ( $n=8-10$ per group) was examined in the following order of testing: elevated plus maze (EPM); sociability and social novelty preference; spontaneous alternation; novel object recognition; delayed alternation. All animals were assessed by an observer blinded to genotype and treatment, before killing at PDs 150-160.

\section{Behavioral Measures}

Exploratory activity. Each mouse was placed individually in the center of an open field apparatus $\left(27.9 \times 27.9 \mathrm{~cm}^{2}\right.$; ENV510, Med Associates, St Albans, VT, USA). Total ambulatory counts, distance traveled $(\mathrm{cm})$, and vertical activity were recorded over a period of $240 \mathrm{~min}$.

Spontaneous alternation. Spatial working memory was assessed using the continuous variant of the Y-maze spontaneous alternation procedure (Lalonde, 2002; Hughes, 2004) as described previously (O'Tuathaigh et al, 2007; Babovic et al, 2008). Briefly, the Y-maze apparatus consisted of three identical arms $\left(\right.$ each $\left.40 \times 12.5 \times 40 \mathrm{~cm}^{3}\right)$. Without previous habituation, each test mouse was placed at the center of the Y maze and allowed to move freely throughout the maze for a single 10-min period. Spontaneous alternation 
was defined as successive entries into the three arms, in overlapping triplet sets. It is expressed as a percentage and refers to the ratio of arm choices differing from the previous two choices to the total number of arm entries: percentage alternation $=($ (number of alternations/total number of arm entries $)-2) \times 100$.

Delayed alternation. Spatial working memory was assessed further in terms of the delayed variant of the Y-maze alternation procedure, using a manually operated, modified Y maze (Modular Maze, Med Associates), as described previously for T-maze alternation (Lai et al, 2006). All mice were gradually introduced to a food restriction regimen over a period of 7-10 days, until they had reached $85 \%$ of free-feeding weight. Over a subsequent period of 3 days, mice were habituated to the training environment. They were trained to retrieve reinforcing food pellets $(12 \mathrm{mg}$; TestDiet, Richmond, IN, USA) at the end of each arm; this was followed by 10-12 days during which the mouse was rewarded with a food pellet when a successful alternation was achieved. After mice made at least $70 \%$ correct choices on 2 consecutive days, the testing phase began. For this, delays of 0,15 , or $30 \mathrm{~s}$ were randomly introduced between the sample run and choice run. Mice were given 4 trials of each delay per day of testing, for a total of 12 trials for each delay. Any animal that responded poorly to the food restriction regimen or failed to acquire the alternation task (one adolescent WT treated with vehicle, two adult COMT HET treated with $4 \mathrm{mg} / \mathrm{kg}$ THC) was excluded from the analysis. Owing to the labor intensity of the procedure, this assessment could be conducted only in males.

Novel object recognition. Recognition memory was assessed using the novel object recognition paradigm with two retention intervals ( $5 \mathrm{~min}$ and $1 \mathrm{~h}$ ) and the same arena dimensions and novel objects as described previously (Babovic et al, 2008). The experiment was conducted under standard room lighting and proceeded according to the following stages:

(1) Habituation phase: Twenty four hours before testing, mice were placed in the arena and allowed to explore freely for two consecutive sessions of $30 \mathrm{~min}$ each, with an intersession interval of $15 \mathrm{~min}$.

(2) Sample phase: Mice were first allowed to explore the arena for two further sessions of $30 \mathrm{~min}$, separated by an inter-session interval of $15 \mathrm{~min}$. Two identical objects, A1 and A2, were then placed at the rear left and right corners of the arena, $5 \mathrm{~cm}$ from both walls to facilitate exploration around each object. Each test mouse was placed at the midpoint of the wall opposite to the sample objects, with nose facing the wall and away from objects, to remove any unintentional bias, and allowed to explore the arena for $5 \mathrm{~min}$. Time spent interacting with each object was recorded manually. At the end of the sample phase, the test mouse was returned to its home cage.

(3) Test phase 1: After an inter-trial interval of $5 \mathrm{~min}$, the test mouse was placed in the arena now containing familiar object A1 and novel object B1 for $5 \mathrm{~min}$. Time spent interacting with each object was recorded manually for $5 \mathrm{~min}$.
(4) Test phase 2: After an inter-trial interval of $1 \mathrm{~h}$ (ie, the period between completion of test phase 1 and start of test phase 2), the test mouse was placed in the arena now containing familiar object B1 and novel object $\mathrm{C} 1$. Time spent interacting with each object was recorded manually for $5 \mathrm{~min}$. Both the sequence of object presentation and the position of familiar/novel objects were counterbalanced between animals. Time spent interacting with each object was determined as nose or whiskers touching the object or directed toward it within $<1 \mathrm{~cm}$, or touching the object with a paw. Accidental contact with object (ie, bumping or using the object as a platform to explore the arena) was not counted as interaction with the object.

Sociability and social novelty preference. This task has been used to provide an easily quantifiable measure of affiliative behavior and behavioral response to social novelty (Moy et al, 2004; Sankoorikal et al, 2006). Sociability and social novelty preference were assessed in a three-chamber apparatus using a two-stage paradigm, as detailed previously (O'Tuathaigh et al, 2007; Babovic et al, 2008):

(1) Sociability: Before the sociability phase, the test mouse was allowed a $15-\mathrm{min}$ habituation period during which the two doors connecting the three chambers were opened, enabling free access to the entire apparatus. After this habituation phase, an unfamiliar same-sex C57BL6 mouse (Stranger 1) was placed in either the left or right chamber enclosed in a small, internal wire cage $\left(10 \times 10 \times 12 \mathrm{~cm}^{3}\right)$, which allowed nose contact; placement of the Stranger mouse in the left or right chamber alternated between trials, with an empty but otherwise identical wire cage in the opposite chamber. Each Stranger mouse had been habituated to placement in the small, internal wire cage $24 \mathrm{~h}$ before testing. After placement of the Stranger mouse into the left or right chamber, both doors to these side chambers were then opened, and the test mouse was allowed to leave the center chamber and explore all three chambers of the apparatus for a period of $10 \mathrm{~min}$. Entry into either chamber was defined as all four paws in that chamber.

(2) Social novelty preference: Following the sociability phase, each test mouse was immediately returned to the center chamber and the doors to the side chambers were closed. There followed a second session to measure social preference for a novel Stranger. With the initial Stranger 1 (now Familiar) retained in its original chamber, a second, Stranger 2 mouse (Novel) was placed in the previously empty but otherwise identical small wire cage in the opposite chamber. After placement of the Novel mouse into the chamber opposite to that still containing the Familiar mouse, both doors to the side chambers were opened, and the test mouse was allowed to leave the center chamber and explore all three chambers of the apparatus for another period of $10 \mathrm{~min}$. In the assessment of social novelty preference, all other parameters and measures were as described above for assessment of sociability.

Elevated plus maze. Emotional/anxiety-related behavior was assessed in the EPM (Pellow and File, 1986) as outlined previously (Babovic et al, 2010). The EPM consisted of two opposing arms surrounded by cream-colored, chipboard walls (closed arms; $12 \mathrm{~cm}$ high, $9 \mathrm{~cm}$ wide) and 
two opposing arms devoid of walls (open arms) elevated $25 \mathrm{~cm}$ above ground level under dim lighting conditions ( $>50$ lux). Cumulative time spent in open (aversive) and closed (nonaversive) arms was recorded during a 5-min session, together with the number of entries into each arm as defined by all four paws being placed in that arm; an increase or decrease in time spent in the open arm reflects, respectively, a decrease or increase in 'anxiety,' with total number of arm entries reflecting level of 'activity.'

\section{Statistical Analysis}

This followed procedures similar to those described previously (O'Tuathaigh et al, 2007, 2010; Babovic et al, 2008), using analysis of variance (ANOVA) with post hoc comparisons by Dunnett's test, corrected for multiple comparisons: exploration in a novel environment was analyzed in terms of activity counts over $1-4 \mathrm{~h}$ of habituation; spontaneous alternation was analyzed in terms of percentage alternation and number of arm entries; delayed alternation was analyzed in terms of latency to reach alternation criterion and percentage correct alternation at each delay interval (mean across trials; 0, 15, $30 \mathrm{~s}$ ); novel object recognition was analyzed in terms of time exploring the novel object during the sample phase, test phase 1, and test phase 2; sociability and social novelty preference were analyzed in terms of total time spent in and number of entries into each chamber; and the EPM was analyzed in terms of absolute or percentage time spent in and number of entries into each arm.

For the above phenotypic measures, we hypothesized a priori that drug treatment would be modulated by treatment age and sex (see the 'Introduction' section, Desbonnet et al, 2009; Kirby et al, 2010); thus, where appropriate, separate ANOVA analyses were also conducted within adolescent-treated, adult-treated, male and female groups. Although the focus of these analyses is on whether the effects of chronic THC were modified by the COMT genotype in relation to age at treatment, a number of ancillary findings on general responsivity to chronic THC in relation to age at treatment and sex, in a manner unrelated to genotype, are reported separately in Supplementary data. All statistical analyses were carried out using the SPSS software package (Version 14, SPSS, Chicago, IL, USA).

\section{RESULTS}

\section{Exploratory Activity}

All groups readily displayed habituation in terms of reduction in activity counts over $1-4 \mathrm{~h}$ of exploration (effect of hours: $\mathrm{F}(3,269)=410.00, p<0.001)$. Among adolescenttreated mice, the effects of THC on activity differed between the genotypes over time in a manner that varied between the sexes (drug $\times$ genotype $\times$ hours $\times$ sex interaction: $\mathrm{F}(12,145)=1.98, p=0.03)$; over $1 \mathrm{~h}$, THC increased exploratory activity in male COMT HET at $8.0 \mathrm{mg} / \mathrm{kg}$ and in male COMT KO at 4.0 and $8.0 \mathrm{mg} / \mathrm{kg}$ (Table 1). No such effects were evident in female adolescent-treated mice or in either male or female adult-treated mice. See also Supplementary data.

\section{Spontaneous Alternation}

WT mice receiving vehicle displayed typical spontaneous alternation. In male adolescent-treated mice, THC disrupted alternation in a manner that differed between the genotypes $($ drug $\times$ genotype interaction: $\mathrm{F}(4,79)=2.81, p=0.03$ ), whereas vehicle-treated COMT KO showed an increase in alternation, $8.0 \mathrm{mg} / \mathrm{kg}$ THC increased alternation in COMT HET but reduced alternation in COMT KO (Figure 1a). In female adolescent-treated mice, chronic THC disrupted alternation in a manner unrelated to genotype (effect of drug: $\mathrm{F}(2,67)=5.09, p<0.01) ; 8.0 \mathrm{mg} / \mathrm{kg}$ THC reduced alternation in both WT and COMT KO (Figure 1c). No such effects on alternation were evident in either male or female adult-treated mice (Figures $1 \mathrm{~b}$ and $\mathrm{d}$ ), and no corresponding effects on number of arm entries were evident in either male or female adolescent- or adult-treated mice (data not shown). See also Supplementary data.

\section{Delayed Alternation}

During training, there were no effects of genotype or treatment on time to reach at least $70 \%$ correct alternation. WT mice receiving vehicle displayed typical delayed alternation. Among experimental groups (males only; see the 'Methods' section), there were no effects of THC or genotype, or interactions with genotype, in terms of latency to reach the $70 \%$ correct criterion and alternation using either the 0 -s or 30-s delay interval; vehicle-treated COMT $\mathrm{KO}$ exhibited an increase in alternation at the 15-s interval relative to WT $(\mathrm{t}(15)=2.18, p<0.05)$ (Figure $2 \mathrm{a})$. However, at the 30-s delay interval, in adolescent-treated mice, THC disrupted alternation in a manner that differed between the genotypes (drug $\times$ genotype $\times$ treatment age interaction: $\mathrm{F}(4,129)=2.78, p=0.04)$, whereas vehicle-treated COMT KO showed an increase in alternation at the 15-s interval relative to WT $(\mathrm{t}(15)=2.18, p<0.05)$ (Figure $2 \mathrm{a})$. No such effects on delayed alternation were evident in adult-treated mice (Figure $2 \mathrm{~b}$ ).

\section{Novel Object Recognition}

WT mice receiving vehicle displayed typical recognition of the novel object at the 5-min retention interval, which weakened at the 1-h retention interval. Among experimental groups, there were no effects of THC or genotype, or interactions with genotype, in terms of duration of object exploration during the sample phase or at the 5-min retention interval (test phase 1); at the 1-h retention interval (test phase 2), THC administered during either adolescence or adulthood disrupted recognition (effect of drug: $\mathrm{F}(2,255)=3.43, \quad p=0.03$;) but there were no effects of genotype or interactions with genotype (Table 2). See also Supplementary data.

\section{Sociability and Social Novelty Preference}

During the sociability phase, all experimental groups demonstrated a preference for spending more time in, and making more entries into, the chamber containing the unfamiliar mouse relative to the opposite, empty chamber (effect of chamber: time, $\mathrm{F}(1,244)=58.10, p<0.001$; entries, 
Table I Exploratory Activity (Ambulatory Counts; Means \pm SEM, $n=8-10$ Per Group) in the Open Field During I-4h in Male and Female WT, COMT HET, and COMT KO Mice After Adolescent vs Adult THC (4.0, $8.0 \mathrm{mg} / \mathrm{kg})$ or vehicle $(\mathrm{VEH})$

\begin{tabular}{|c|c|c|c|c|c|c|c|c|}
\hline & \multicolumn{4}{|c|}{ Adolescent } & \multicolumn{4}{|c|}{ Adult } \\
\hline & Hour I & Hour 2 & Hour 3 & Hour 4 & Hour I & Hour 2 & Hour 3 & Hour 4 \\
\hline \multicolumn{9}{|l|}{ WT } \\
\hline VEH & $2855 \pm 325$ & $849 \pm 171$ & $298 \pm 87$ & $377 \pm 249$ & $3503 \pm 456$ & $694 \pm 231$ & $702 \pm 154$ & $641 \pm 173$ \\
\hline \multicolumn{9}{|l|}{ HET } \\
\hline VEH & $2606 \pm 229$ & $635 \pm 104$ & $337 \pm 76$ & $416 \pm 149$ & $2615 \pm 438$ & $1009 \pm 224$ & $613 \pm 25 \mid$ & $463 \pm 225$ \\
\hline THC (4 mg/kg) & $2649 \pm 309$ & $625 \pm 74$ & $669 \pm 140$ & $564 \pm 156$ & $2722 \pm 460$ & $1389 \pm 312$ & $487 \pm 187$ & $324 \pm 163$ \\
\hline $\mathrm{THC}(8 \mathrm{mg} / \mathrm{kg})$ & $3359 \pm 380 *$ & $791 \pm 122$ & $654 \pm|4|$ & $722 \pm 202$ & $3269 \pm 185$ & $814 \pm 182$ & $591 \pm 108$ & $337 \pm 124$ \\
\hline \multicolumn{9}{|l|}{$\mathrm{KO}$} \\
\hline \multicolumn{9}{|l|}{ Females } \\
\hline \multicolumn{9}{|l|}{ WT } \\
\hline VEH & $2943 \pm 177$ & $735 \pm 134$ & $515 \pm 155$ & $709 \pm 280$ & $3166 \pm 194$ & $629 \pm 88$ & $366 \pm 112$ & $513 \pm 188$ \\
\hline THC (4 mg/kg) & $2656 \pm 485$ & $813 \pm 129$ & $374 \pm 78$ & $530 \pm 160$ & $3054 \pm 365$ & $813 \pm 129$ & $502 \pm 116$ & $317 \pm 201$ \\
\hline THC (8 mg/kg) & $289 \mid \pm 203$ & $1649 \pm 489$ & $1122 \pm 359$ & $1112 \pm 191$ & $289 \mid \pm 203$ & $889 \pm 357$ & $754 \pm 219$ & $616 \pm 119$ \\
\hline \multicolumn{9}{|l|}{ HET } \\
\hline VEH & $2808 \pm 380$ & $936 \pm 184$ & $617 \pm 215$ & $499 \pm 140$ & $2760 \pm 276$ & $|10| \pm 277$ & $837 \pm 231$ & $310 \pm 77$ \\
\hline $\mathrm{THC}(4 \mathrm{mg} / \mathrm{kg})$ & $3167 \pm 399$ & $996 \pm 163$ & $536 \pm 169$ & $579 \pm 137$ & $2897 \pm 220$ & $807 \pm 218$ & $438 \pm 290$ & $277 \pm 117$ \\
\hline THC (8 mg/kg) & $3328 \pm 523$ & $1452 \pm 435$ & $903 \pm 358$ & $895 \pm 377$ & $3013 \pm 412$ & $1016 \pm 399$ & $692 \pm 164$ & $576 \pm 289$ \\
\hline
\end{tabular}

*p $<0.05$ vs VEH-treated controls.

$\mathrm{F}(1,244)=191.00, p<0.001)$; there were no effects of THC or genotype, or interactions with genotype, in relation to the sociability phase (data not shown).

During the social novelty preference phase, all experimental groups now displayed a preference for spending more time in, and making more entries into, the chamber containing the new, unfamiliar mouse relative to the opposite chamber containing the previous, now familiar mouse (effect of chamber: time, $\mathrm{F}(1,244)=71.12, p<0.001$; entries, $\mathrm{F}(1,244)=$ $32.62, p<0.001)$. THC treatment disrupted social novelty preference (chamber $\times$ drug: time, $\mathrm{F}(2,244)=7.08, p=0.001$; entries, $\mathrm{F}(2,244)=9.68, p<0.001)$, but there were no effects of genotype, or interactions with genotype (Figure 3). See also Supplementary data.

\section{Elevated Plus Maze}

All experimental groups typically spent the majority of their time in the closed arms of the EPM. An effect of THC to increase time spent in the open arms (effect of drug:
$\mathrm{F}(2,261)=5.54, p=0.004)$ differed between the genotypes in a manner that varied with treatment age and between the sexes (drug $\times$ genotype $\times$ treatment age $\times$ sex interaction: $\mathrm{F}(4,261)=2.39, p=0.04)$, whereas THC increased the time spent in the open arms in male, adolescent-treated COMT $\mathrm{KO}$ at 4.0 and $8.0 \mathrm{mg} / \mathrm{kg}$, no such effects were evident in female adolescent-treated mice or in either male or female adult-treated mice (Table 3). THC increased the percentage of open arm entries (effect of drug: $\mathrm{F}(2,261)=3.81$, $p=0.02)$ in a manner that did not differ between either the genotypes or the sexes; no effect of THC or genotype was evident on number of closed arm entries. See also Supplementary data.

\section{DISCUSSION}

This study uses COMT HET and KO mice of both sexes to examine the effects of the COMT gene on behavioral responsivity to chronic THC administered over adolescence, 
a

Adolescent males:

Spontaneous Alternation

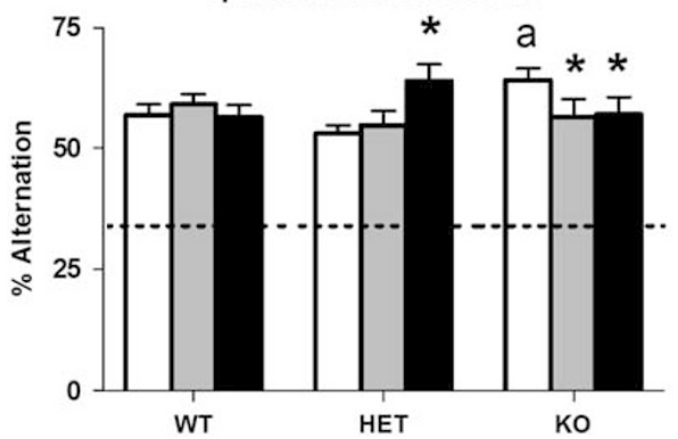

C

Adolescent females:

75 Spontaneous Alternation

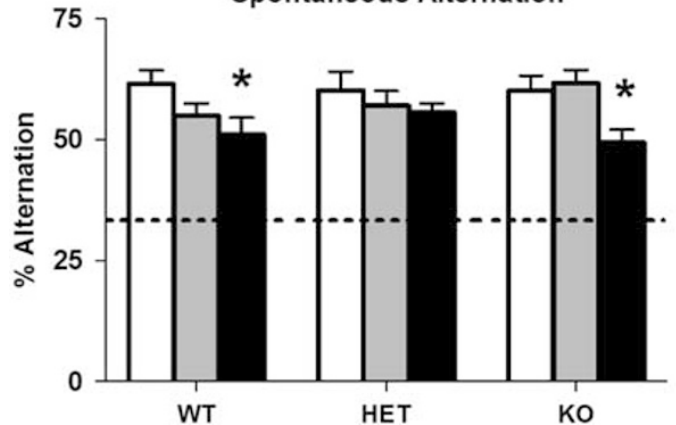

b
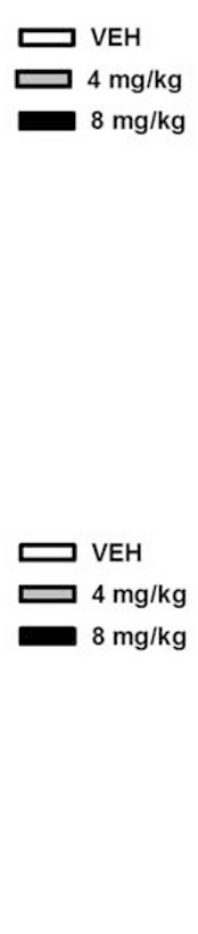

\section{Spontaneous Alternation}

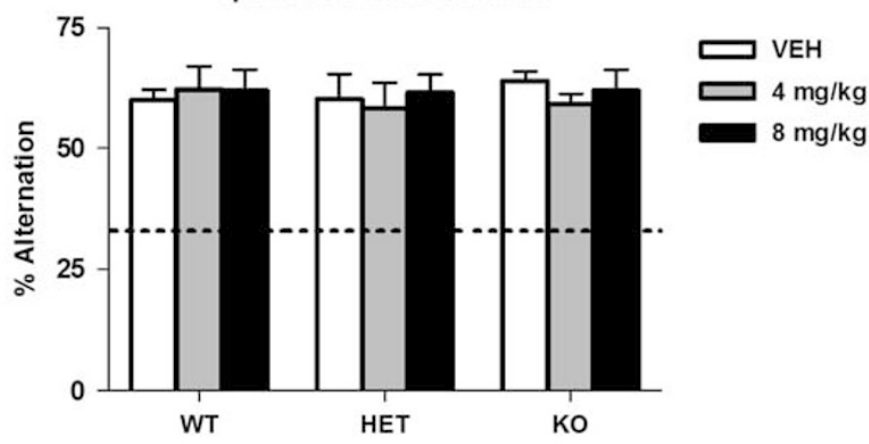

d Adult females:

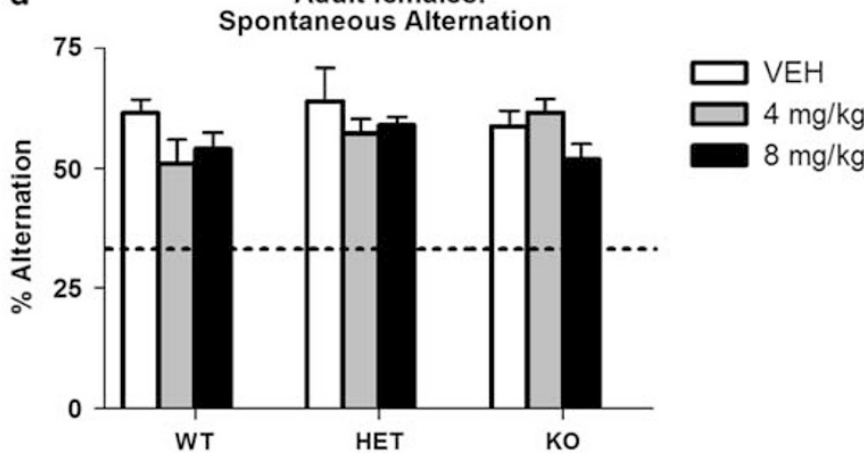

Figure I (a-d) Spontaneous alternation (\% alternation; means \pm SEM, $n=8-10$ per group) in male and female WT, COMT HET, and COMT KO mice after adolescent male (panel a) vs adult male (panel b) or adolescent female (panel c) vs adult female (panel d) THC (4.0, 8.0 mg/kg) or vehicle (VEH); ${ }^{*} p<0.05$ vs VEH-treated controls; ${ }^{a} p<0.05$ vs WT. The dotted line indicates chance performance levels in this task (33\%).
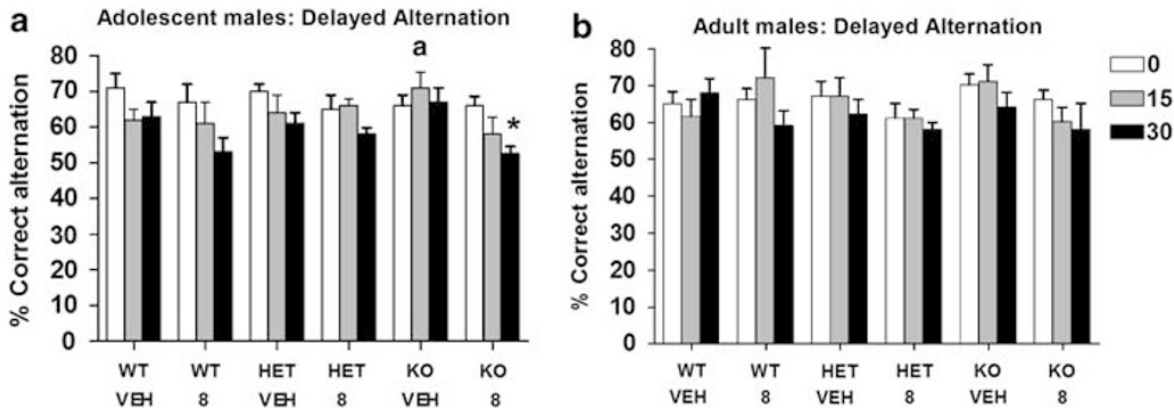

Figure 2 ( $a$ and b) Delayed alternation (\% correct alternation; means \pm SEM, $n=8-10$ per group) at the 0-, I5-, and 30-s intervals in male WT, COMT HET, and COMT KO mice after adolescent (panel a) vs adult (panel b) THC ( $8.0 \mathrm{mg} / \mathrm{kg}$ ) or vehicle (VEH); * ${ }^{*}<0.05$ vs VEH-treated controls; ${ }^{2} p<0.05$ vs WT.

in comparison with chronic THC administered over adulthood, using various phenotypic assessments related to psychosis. As summarized in Table 4, in the present gene $\times$ environment interaction paradigms, adolescent THC administration induces a larger increase in exploratory activity, greater impairment in spatial working memory, in terms of both spontaneous and delayed alternation, and a stronger anti-anxiety effect in COMT KO than in WT, primarily among males; no such genotype- or sex-specific effects of adolescent THC administration were evident for novel object recognition and social behavior, in terms of both sociability and social novelty preference; no such effects of adult THC administration were evident for any behavior. Rather, both adolescent and adult
THC administration disrupted novel object recognition performance and social novelty preference, independent of genotype.

\section{COMT Modulation of Adolescent vs Adult THC Effects}

Exploratory Activity. Spontaneous or psychostimulantinduced locomotor hyperactivity in a novel environment has long been associated with increases in mesolimbic DAergic transmission and is commonly adopted as a DA-linked 'proxy' measure of positive, psychotic symptoms (Rebec, 2006; Howes and Kapur, 2009; Perry et al, 2009; Van den Buuse, 2010). Although acute cannabis administration increases DAergic neuronal activity and DA release 
Table 2 Novel Object Recognition (\% Novel Object Preference; Means \pm SEM, $n=16-30$ Per Group) at the 5-min (Test Phase I) and I-h Retention Interval (Test Phase 2) in WT, COMT HET, and COMT KO Mice (Males And Females Composited) After Adolescent vs Adult $\mathrm{THC}(4.0,8.0 \mathrm{mg} / \mathrm{kg})$ or Vehicle $(\mathrm{VEH})$

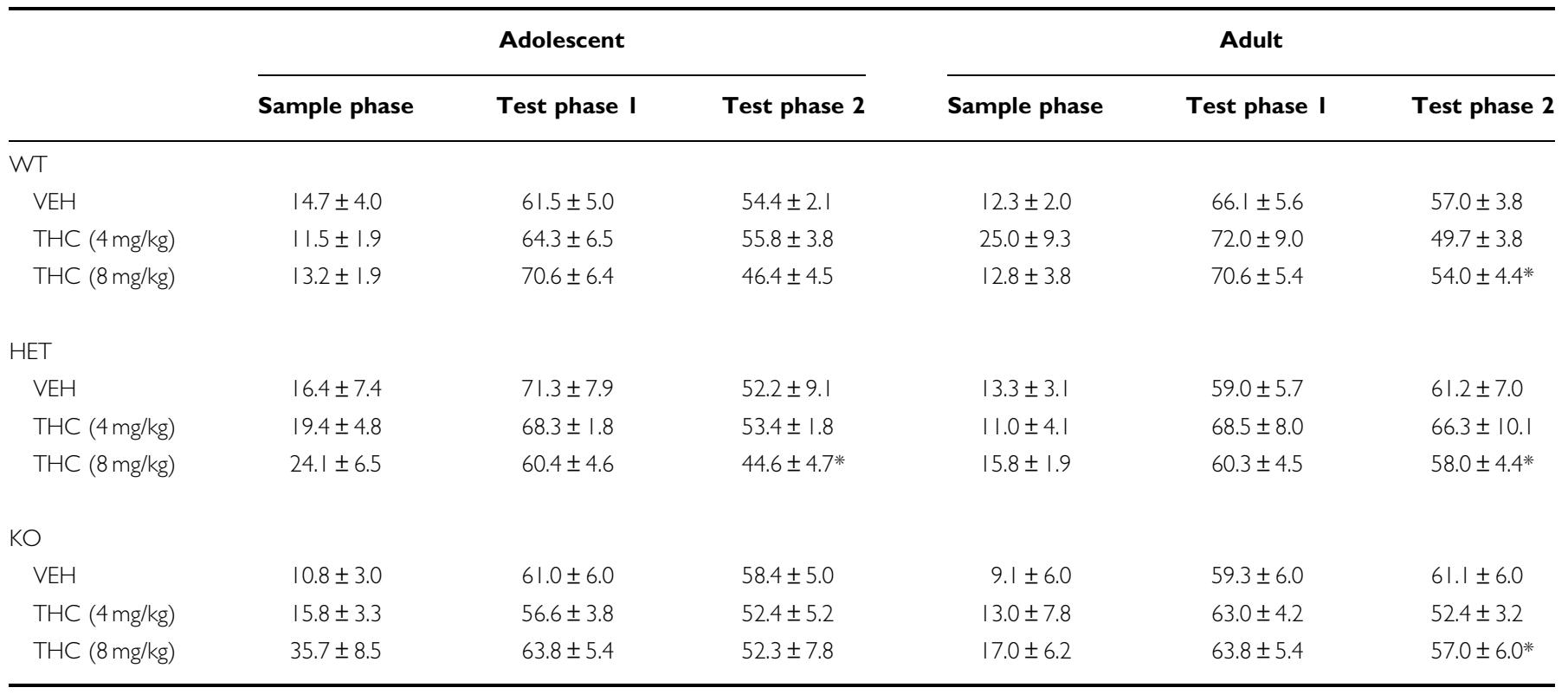

*p $<0.05$ vs VEH-treated controls.
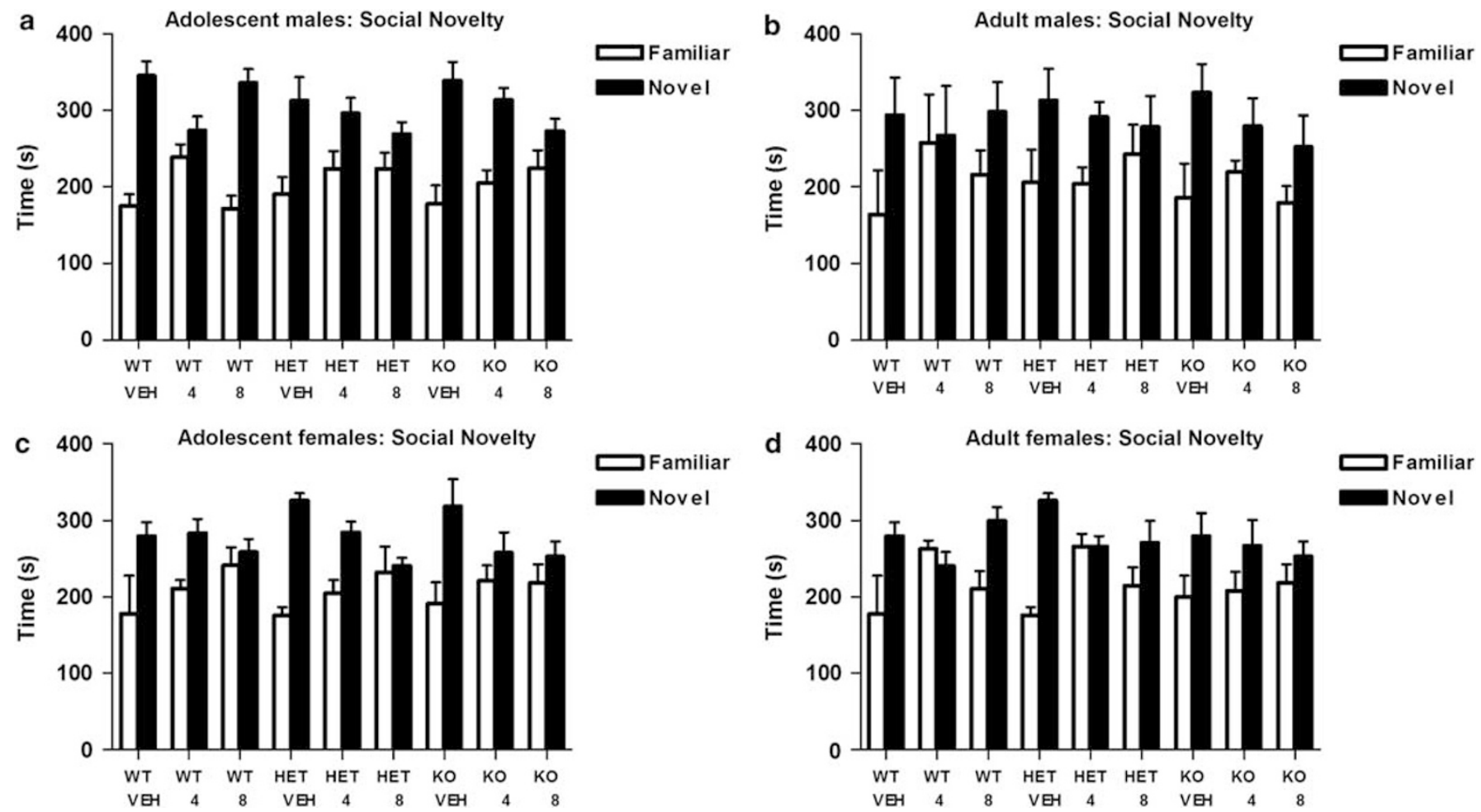

Figure 3 (a-d) Social novelty (Familiar vs Novel) preference times (s; means \pm SEM, $n=8-10$ per group) in male and female WT, COMT HET, and COMT $\mathrm{KO}$ mice after adolescent male (panel a) vs adult male (panel b) or adolescent female (panel c) vs adult female (panel d) THC (4.0, $8.0 \mathrm{mg} / \mathrm{kg}$ ) or vehicle (VEH).

in terminal fields, both in animals and humans (Murray et al, 2007; Bossong et al, 2009), the absence here of any overall effect of chronic cannabis administration over adolescence on exploratory activity in adulthood is in keeping with a recent report (Rubino et al, 2008).
Previous studies in COMT-deficient mice have shown few changes in DA metabolism or overflow in the dorsal striatum (Yavich et al, 2007). However, although the role of COMT in subcortical DA function seems to be lower than in the PFC, it may have an important role in regulating the 
Table 3 Time Spent in the Open Arm (\% Time in Open Arm; Means \pm SEM, $n=8-10$ per Group) in the Elevated Plus Maze in WT, COMT HET, and COMT KO Mice After Adolescent vs Adult $\mathrm{THC}(4.0,8.0 \mathrm{mg} / \mathrm{kg})$ or Vehicle $(\mathrm{VEH})$

\section{\% Time in open arm}

Adolescent Adult

\begin{tabular}{|c|c|c|}
\hline \multicolumn{3}{|l|}{ Males } \\
\hline \multicolumn{3}{|l|}{ WT } \\
\hline VEH & $6.1 \pm 2.1$ & $6.3 \pm 1.3$ \\
\hline THC (4 mg/kg) & $10.1 \pm 1.6$ & $8.5 \pm 2.1$ \\
\hline THC (8 mg/kg) & $6.3 \pm 1.5$ & $7.9 \pm 1.8$ \\
\hline \multicolumn{3}{|l|}{ HET } \\
\hline VEH & $5.9 \pm 2.7$ & $7.2 \pm 1.3$ \\
\hline THC (4 mg/kg) & $10.5 \pm 2.5$ & $9.4 \pm 3.1$ \\
\hline THC (8 mg/kg) & $9.7 \pm 2.4$ & $10.6 \pm 2.0$ \\
\hline \multicolumn{3}{|l|}{$\mathrm{KO}$} \\
\hline VEH & $8.2 \pm 2.1$ & $9.0 \pm 2.8$ \\
\hline THC (4 mg/kg) & $17.5 \pm 3.0 *$ & $11.4 \pm 3.1$ \\
\hline THC (8 mg/kg) & $25.1 \pm 5.0 *$ & $11.6 \pm 2.0$ \\
\hline \multicolumn{3}{|l|}{ Females } \\
\hline \multicolumn{3}{|l|}{ WT } \\
\hline VEH & $9.6 \pm 3.0$ & $12.3 \pm 2.8$ \\
\hline THC (4 mg/kg) & $20.5 \pm 2.3$ & $19.5 \pm 2.3$ \\
\hline THC (8 mg/kg) & $18.1 \pm 4.8$ & $16.1 \pm 4.8$ \\
\hline \multicolumn{3}{|l|}{ HET } \\
\hline VEH & $16.1 \pm 2.7$ & $9.0 \pm 0.9$ \\
\hline THC (4 mg/kg) & $18.6 \pm 4.5$ & $12.3 \pm 2.2$ \\
\hline THC (8 mg/kg) & $12.8 \pm 4.1$ & $11.6 \pm 1.9$ \\
\hline \multicolumn{3}{|l|}{$\mathrm{KO}$} \\
\hline VEH & $16.9 \pm 4.8$ & $\mid 4.8 \pm 3.1$ \\
\hline THC (4 mg/kg) & $25.6 \pm 9.0$ & $21.8 \pm 4.8$ \\
\hline THC (8 mg/kg) & $18.2 \pm 3.0$ & $15.9 \pm 2.0$ \\
\hline
\end{tabular}

*p $<0.05$ vs VEH-treated controls.

Table 4 Summary of Phenotypes of WT, COMT HET, and COMT KO Mice After Adolescent or Adult THC Treatment

\begin{tabular}{|c|c|c|c|c|c|c|}
\hline \multirow[t]{2}{*}{ Phenotype } & \multicolumn{3}{|c|}{ Adolescent } & \multicolumn{3}{|c|}{ Adult } \\
\hline & WT & HET & KO & WT & HET & KO \\
\hline Exploratory activity & $=$ & $=$ & $\uparrow^{a}$ & $=$ & $=$ & $=$ \\
\hline Spontaneous alternation & $=$ & $=$ & $\downarrow^{\mathrm{a}}$ & $=$ & $=$ & $=$ \\
\hline Delayed alternation & $=$ & $=$ & $\downarrow^{a}$ & $=$ & $=$ & $=$ \\
\hline Novel object recognition & $\downarrow$ & $\downarrow$ & $\downarrow$ & $\downarrow$ & $\downarrow$ & $\downarrow$ \\
\hline Sociability & $=$ & $=$ & $=$ & $=$ & $=$ & $=$ \\
\hline Social novelty preference & $\downarrow$ & $\downarrow$ & $\downarrow$ & $\downarrow$ & $\downarrow$ & $\downarrow$ \\
\hline Elevated plus maze & $=$ & $=$ & $\downarrow^{\mathrm{a}}$ & $=$ & $=$ & $=$ \\
\hline
\end{tabular}

Summary of phenotypes for WT, COMT HET, and COMT KO mice after adolescent vs adult THC $(4.0,8.0 \mathrm{mg} / \mathrm{kg})$ or vehicle $(V E H) ;=$ no significant difference relative to $\mathrm{VEH}$; $\downarrow$ lower than $\mathrm{VEH}$; $\uparrow$ greater than $\mathrm{VEH}$.

${ }^{a}$ Effect observed in males only. balance and interplay of cortical $v s$ subcortical DA transmission, primarily in males (Gogos et al, 1998; Huotari et al, 2004). Furthermore, DA content, fiber density, and receptor density reach peak levels during adolescence and thereafter undergo pruning in several brain regions, including the striatum and PFC (Hohn and Wuttke, 1979; Kalsbeek et al, 1988; Teicher et al, 1995; Tarazi et al, 1999). Therefore, although some effects of neophobia cannot be excluded, adolescent THC exposure in COMT mutants and the associated sex-specific hyper-exploratory phenotype in adulthood may, at least in part, reflect this DAergic developmental trajectory and the increased basal level of PFC DA observed in male COMT KO (Gogos et al, 1998).

\section{Spatial Working Memory}

The fact that vehicle-treated male COMT KO evidence modest but consistent improvement in spatial working memory, as assessed using both spontaneous and delayed alternation, is in accordance with recent phenotypic studies in COMT mutants (Babovic et al, 2008; Papaleo et al, 2008). Studies in both rodents and humans show that cortical DA signaling, specifically DAergic activity through PFC D1 receptors, affects cognitive performance with an inverted U-shaped relationship, such that either deficient or excessive DAergic activity can exert deleterious effects (Goldman-Rakic et al, 2000; Mattay et al, 2003; Seamans and Yang, 2004; Tunbridge et al, 2006). In COMT KO, tissue levels, turnover, and overflow of DA are increased in the PFC but not in the striatum (Gogos et al, 1998; Huotari et al, 2002; Yavich et al, 2007). Thus, the present finding of improvement in spatial working memory in vehicle-treated male COMT KO is consistent with their having higher PFC DA levels.

Adolescent THC exposure has been reported previously to result in disruption of the spatial working memory in adulthood (Rubino et al, 2009). In this study, the improvement in spatial working memory in male COMT $\mathrm{KO}$ was found to be particularly sensitive to the disruptive effects of adolescent THC on cognitive function, as indexed by impairment in spontaneous and delayed alternation. The present heightening of this disruptive effect in male COMT $\mathrm{KO}$ is congruent with the effect of acute amphetamine on working memory in COMT KO (Papaleo et al, 2008), and with the effect of heightened mesoprefrontal DAergic activity by cannabinoid receptor 1 (CB1) activation to impair working memory (Jentsch et al, 1997; Pistis et al, 2001). Given that both deficient and excessive DAergic activity in the PFC can lead to impairment in PFC-related cognitive function, and the critical importance of adolescence in the development of DA systems, heightening of the disruptive effects of adolescent THC exposure on PFCmediated working memory processes in male COMT KO is likely mediated by PFC DA dysfunction. On this basis, it is proposed that decreased availability of DA in the PFC, by sex-specific genetic deficiency in COMT function, may mediate adolescent THC-induced long-term impairment in cognitive processes, such as working memory, which are 'core' deficits in schizophrenia (Aleman et al, 1999). 


\section{Recognition Memory}

In a previous study, we showed a modest phenotypic reduction in object recognition memory in COMT HET relative to other genotypes (Babovic et al, 2008); although the present investigation failed to replicate this effect, different retention times were used between these studies. Both adolescent and adult THC exposure disrupted novel object recognition performance at the longest retention interval, but in a manner unrelated to genotype. These findings contrast with those above in relation to spatial working memory, in which the disruptive effects of THC were found to vary with the COMT genotype in a manner dependant on age at treatment and sex.

Although spatial working memory depends primarily on the PFC (Goldman-Rakic et al, 2000; Seamans and Yang, 2004; Tunbridge et al, 2006), recognition memory for novel $v s$ familiar objects does not depend on the PFC but involves primarily medial temporal lobe structures, particularly the hippocampus (Hammond et al, 2004; Ainge et al, 2006; DeVito and Eichenbaum, 2009) and perirhinal cortex (Brown and Aggleton, 2001; Barker et al, 2007; Squire et al, 2007). Consistent with the present profile of differential cognitive deficits after adolescent THC exposure in mice, chronic THC exposure in rats has been associated with deficits in recognition memory, accompanied by changes in hippocampal proteomics (Quinn et al, 2008), and fewer synaptic contacts and/or less efficient synaptic connections throughout the hippocampus (Rubino et al, 2009). Interestingly, although in schizophrenia, impairment of spatial working memory is a 'core' cognitive deficit, recognition memory seems less impaired and varies greatly across studies (Aleman et al, 1999).

\section{Social Behavior}

The present finding that COMT mutants show no alterations in either sociability or social novelty preference replicates our previous report (Babovic et al, 2008). Although chronic THC exposure over either adolescence or adulthood was without effect on sociability, both exposures disrupted social novelty preference; this effect of THC is similar to the phenotype of untreated mice mutant for the schizophrenia risk gene neuregulin 1 (O'Tuathaigh et al, 2007). Residual social interaction deficits have also been reported after adolescent administration of a synthetic cannabinoid analog in rats (O'Shea et al, 2004) and of THC in mice (Quinn et al, 2008). We could not identify any material influence of the COMT genotype on the effects of THC for either sociability or social novelty preference.

\section{Anxiety \\ Overall, chronic THC exposure resulted in an 'anxiolytic' effect in the EPM. Acutely, cannabinoid agonists can induce anxiolytic-like effects at lower doses and anxiogenic-like effects at higher doses, in a manner that can differ between adolescent and adult animals (Viveros et al, 2005a, ). Rodent models of chronic exposure across diverse paradigms have produced conflicting results, with studies reporting anxiety- like behavior to be decreased, particularly using the EPM}

(Biscaia et al, 2003; Schramm-Sapyta et al, 2007; Wegener and Koch, 2009), unaltered (Rubino et al, 2009) or increased (O'Shea et al, 2004, 2006). In humans, adolescent cannabis exposure has been associated with depressive and/or anxiety disorders, in addition to psychosis (Patton et al, 2002). Studies in COMT KO mice have indicated anxietylike behavior to be either increased, particularly using the light-dark paradigm (Gogos et al, 1998; Papaleo et al, 2008), or unaltered (Haasio et al, 2003). In humans, the lowactivity COMT Met allele has been linked to increased levels of anxiety (Drabant et al, 2006; Heinz and Smolka, 2006; Harrison and Tunbridge, 2008).

Our finding in the EPM, of an anxiolytic-like effect of THC that was most evident in male COMT KO exposed during adolescence, indicates a complex interaction between genotype, age at treatment, and sex. Sexual dimorphism in the COMT mutant phenotype has been reported for aggression, emotional reactivity, and aspects of cognition (Gogos et al, 1998; Babovic et al, 2008), and it has been suggested that an interaction between cannabinoid receptors and estrogen receptors in rodents may explain why adolescent males find cannabinoids less aversive than adult males (Quinn et al, 2008). Estrogen may have an important role in the downregulation of COMT transcription (Xie et al, 1999), such that sexual dimorphism in phenotypic effects may reflect the involvement of sexspecific compensatory mechanisms (a necessary factor to consider in relation to all constitutive $\mathrm{KO}$ mice) and/or transcriptional regulation by estrogens (Gogos et al, 1998; Harrison and Tunbridge, 2008). These data elaborate this evolving body of evidence to include responsivity to THC.

\section{Summary}

These studies illuminate recent clinical finding that (1) the relationship between cannabis use during adolescence and subsequent psychosis is influenced by the human COMT genotype (Caspi et al, 2005); and (2) across young, mostly male patients, relatives, and unrelated controls, the association of acute THC administration with increased expression of psychosis liability and memory impairment, in terms of both immediate and delayed recall, is influenced by the COMT genotype (Henquet et al, 2006). In humans, the high-activity COMT Val108Met allele is associated with increased risk for psychosis consequent to THC exposure; thus, it might have been expected that in mutant mice, COMT KO would decrease psychosis-related behavioral effects of THC. The fact that COMT KO increased rather than decreased these effects may reflect complexities in the inverted U-shaped relationship between PFC-mediated function and cortical DAergic activity in human/nonhuman primates vis-à-vis rodents (Seamans and Yang, 2004; Tunbridge et al, 2006); thus, the directionality of the present findings may be less germane. It should be also noted that putative compensatory processes in COMT mutants may contribute to these phenotypes. Nonetheless, these findings indicate processes through which adolescent THC exposure could result in deleterious effects on several aspects of normal, adult functioning that are disrupted in schizophrenia, in a manner that is modulated by the COMT genotype. More importantly, they indicate how genetic, 
developmental, and environmental factors interact to increase individual vulnerability to psychosis.

\section{ACKNOWLEDGEMENTS}

These studies were supported by the Science Foundation Ireland (JLW: 07/IN.1/B960; DRC: 05/RFP/BMI0016) and the Health Research Board (CMPO'T: PD/2007/20; MC: CSA/2004/1).

\section{DISCLOSURE}

The authors declare no conflict of interest.

\section{REFERENCES}

Ainge JA, Heron-Maxwell C, Theofilas P, Wright de Hoz L, Wood ER (2006). The role of the hippocampus in object recognition in rats: examination of the influence of task parameters and lesion size. Behav Brain Res 167: 183-195.

Aleman A, Hijman R, de Haan EH, Kahn RS (1999). Memory impairment in schizophrenia: a meta-analysis. Am J Psychiatry 156: $1358-1366$.

Arseneault L, Cannon M, Poulton R, Murray R, Caspi A, Moffitt TE (2002). Cannabis use in adolescence and risk for adult psychosis: longitudinal prospective study. BMJ 325: 1212-1213.

Arseneault L, Cannon M, Witton J, Murray RM (2004). Causal association between cannabis and psychosis: examination of the evidence. Br J Psychiatry 184: 110-117.

Ashton CH (2003). Comparing cannabis with tobacco: those who start taking cannabis young have the greatest problems. BMJ 327: 165.

Babovic D, Jiang L, Gantois I, Lawrence AJ, Ferreri V, Schutz G et al (2010). Age-related behavioural phenotype and cellular characterisation of mice with progressive ablation of D1 dopamine receptor-expressing cells. Behav Brain Res 206: 78-87.

Babovic D, O'Tuathaigh CM, O'Connor AM, O'Sullivan GJ, Tighe O, Croke DT et al (2008). Phenotypic characterization of cognition and social behavior in mice with heterozygous versus homozygous deletion of catechol-O-methyltransferase. Neuroscience 155: 1021-1029.

Babovic D, O'Tuathaigh CMP, O'Sullivan GJ, Clifford JJ, Tighe O, Croke DT et al (2007). Exploratory and habituation phenotype of heterozygous and homozygous COMT knockout mice. Behav Brain Res 183: 236-239.

Barker GR, Bird F, Alexander V, Warburton EC (2007). Recognition memory for objects, place, and temporal order: a disconnection analysis of the role of the medial prefrontal cortex and perirhinal cortex. J Neurosci 27: 2948-2957.

Belue RC, Howlett AC, Westlake TM, Hutchings DE (1995). The ontogeny of cannabinoid receptors in the brain of postnatal and aging rats. Neurotoxicol Teratol 17: 25-30.

Biscaia M, Marin S, Fernandez B, Marco EM, Rubio M, Guaza C et al (2003). Chronic treatment with CP 55, 940 during the periadolescent period differentially affects the behavioural responses of male and female rats in adulthood. Psychopharmacology 170: 301-308.

Bossong MG, van Berckel BN, Boellard R, Zuurman L, Schuit RC, Windhorst $\mathrm{AD}$ et al (2009). Delta-9-tetrahydrocannabinol induces dopamine release in the human striatum. Neuropsychopharmacology 34: 759-766.

Brown MW, Aggleton JP (2001). Recognition memory: what are the roles of the perirhinal cortex and hippocampus? Nat Rev Neurosci 2: 51-61.

Caspi A, Moffitt TE, Cannon M, McClay J, Murray R, Harrington H et al (2005). Moderation of the effect of adolescent-onset cannabis use on adult psychosis by a functional polymorphism in the catechol-O-methyltransferase gene: longitudinal evidence of a gene $\mathrm{X}$ environment interaction. Biol Psychiatry 57: 1117-1127.

Cha YM, Jones KH, Kuhn CM, Wilson WA, Swartzwelder HS (2007). Sex differences in the effects of delta9-tetrahydrocannabinol on spatial learning in adolescent and adult rats. Behav Pharmacol 18: 563-569.

Cha YM, White AM, Kuhn CM, Wilson WA, Swartzwelder HS (2006). Differential effects of delta9-THC on learning in adolescent and adult rats. Pharmacol Biochem Behav 83: 448-455.

Desbonnet L, Waddington JL, O’Tuathaigh CMP (2009). Mice mutant for genes associated with schizophrenia: common phenotype or distinct endophenotypes? Behav Brain Res 204: 258-273.

DeVito LM, Eichenbaum H (2009). Distinct contributions of the hippocampus and medial prefrontal cortex to the 'what-wherewhen' components of episodic-like memory in mice. Behav Brain Res (in press).

Drabant EM, Hariri AR, Meyer-Lindenberg A, Munoz KE, Mattay VS, Kolachana BS et al (2006). Catechol-O-methyltransferase val158met genotype and neural mechanisms related to affective arousal and regulation. Arch Gen Psychiatry 63: 1396-1406.

D'Souza DC, Abi-Saab WM, Madonick S, Forselius-Bielen K, Doersch A, Braley G et al (2005). Delta-9-tetrahydrocannabinol effects in schizophrenia: implications for cognition, psychosis and addiction. Biol Psychiatry 57: 594-606.

D’Souza DC, Perry E, MacDougall L, Ammerman Y, Cooper T, Wu YT et al (2004). The psychotomimetic effects of intravenous delta-9-tetrahydrocannabinol in healthy individuals: implications for psychosis. Neuropsychopharmacology 29: 1558-1572.

D'Souza DC, Sewell RA, Ranganathan M (2009). Cannabis and psychosis/schizophrenia: human studies. Eur Arch Clin Neurosci 259: 413-431.

Egan MF, Goldberg TE, Kolachana BS, Callicott JH, Mazzanti CM, Straub RE et al (2001). Effect of COMT Val108/158 Met genotype on frontal lobe function and risk for schizophrenia. Proc Natl Acad Sci USA 98: 6917-6922.

Gogos JA, Morgan M, Luine V, Santha M, Ogawa S, Pfaff D et al (1998). Catechol-O-methyltransferase-deficient mice exhibit sexually dimorphic changes in catecholamine levels and behavior. Proc Natl Acad Sci USA 95: 9991-9996.

Goldman-Rakic PS, Muly EC, Williams GV (2000). D(1) receptors in prefrontal cells and circuits. Brain Res Brain Res Rev 31: 295-301.

Haasio K, Huotari M, Nissinen E, Männistö PT (2003). Tissue histopathology, clinical chemistry and behaviour of adult Comtgene-disrupted mice. J Appl Toxicol 23: 213-219.

Hammond RS, Tull LE, Stackman RW (2004). On the delaydependent involvement of the hippocampus in object recognition memory. Neurobiol Learn Mem 82: 26-34.

Harrison PJ, Tunbridge EM (2008). Catechol-O-methyltransferase (COMT): a gene contributing to sec differences in brain function, and to sexual dimorphism in the predisposition to psychiatric disorders. Neuropsychopharmacology 33: 3037-3045.

Heinz A, Smolka MN (2006). The effects of catechol O-methyltransferase genotype on brain activation elicited by affective stimuli and cognitive tasks. Rev Neurosci 17: 359-367.

Henquet C, Krabbendam L, Spauwen J, Kaplan C, Lieb R, Wittchen HU et al (2005). Prospective cohort study of cannabis use, predisposition for psychosis, and psychotic symptoms in young people. BMJ 330: 11 .

Henquet C, Rosa A, Krabbendam L, Papiol S, Fananas L, Drukker M et al (2006). An experimental study of catechol-O-methyltransferase Val158Met moderation of delta-9-tetrahydrocannabinol-induced effects on psychosis and cognition. Neuropsychopharmacology 31: 2748-2757. 
Hohn KG, Wuttke W (1979). Ontogeny of catecholamine turnover rates in limbic and hypothalamic structures in relation to serum prolactin and gonadotropin levels. Brain Res 179: 281-293.

Howes OD, Kapur S (2009). The dopamine hypothesis of schizophrenia: version III-the final common pathway. Schizophr Bull 35: 549-562.

Hughes RN (2004). The value of spontaneous alternation behaviour $(\mathrm{SAB})$ as a test of retention in pharmacological investigations of memory. Neurosci Biobehav Rev 28: 497-505.

Huotari M, García-Horsman JA, Karayiorgou M, Gogos JA, Männistö PT (2004). D-amphetamine responses in catechol-Omethyltransferase (COMT) disrupted mice. Psychopharmacology 172: $1-10$.

Huotari M, Santha M, Lucas LR, Karayiorgou M, Gogos JA, Männistö PT (2002). Effect of dopamine uptake inhibition on brain catecholamine levels and locomotion in catechol-Omethyltransferase-disrupted mice. J Pharmacol Exp Ther 303: 1309-1316.

Jentsch JD, Andrusiak E, Tran A, Bowers Jr MB, Roth RH (1997). Delta 9-tetrahydrocannabinol increases prefrontal cortical catecholaminergic utilization and impairs spatial working memory in the rat: blockade of dopaminergic effects with HA966. Neuropsychopharmacology 16: 426-432.

Kalsbeek A, Voorn P, Buijs RM, Pool CW, Uylings HB (1988). Development of the dopaminergic innervation in the prefrontal cortex of the rat. J Comp Neurol 269: 58-72.

Kirby B, Waddington JL, O'Tuathaigh CMP (2010). Advancing a functional genomics for schizophrenia: psychopathological and cognitive phenotypes in mutants with gene disruption. Brain Res Bull (in press).

Lai WS, Xu B, Westphal KG, Paterlini M, Olivier B, Pavlidis P et al (2006). Akt1 deficiency affects neuronal morphology and predisposes to abnormalities in prefrontal cortex functioning. Proc Natl Acad Sci USA 103: 16906-16911.

Lalonde R (2002). The neurobiological basis of spontaneous alternation. Neurosci Biobehav Rev 26: 6-23.

Linszen DH, Dingemans PM, Lenior ME (1994). Cannabis abuse and the course of recent-onset schizophrenic disorders. Arch Gen Psychiatry 51: 273-279.

Martinez-Arevalo MJ, Calcedo-Ordonez A, Varo-Prieto JR (1994). Cannabis consumption as a prognostic factor in schizophrenia. Br J Psychiatry 164: 679-681.

Mattay VS, Goldberg TE, Fera F (2003). Catechol-O-methyltransferase Val158-Met genotype and individual variation in the brain response to amphetamine. Proc Natl Acad Sci USA 100: 6186-6191.

McLaughlin CR, Martin BR, Compton DR, Abood ME (1994). Cannabinoid receptors in developing rats: detection of mRNA and receptor binding. Drug Alcohol Depend 36: $27-31$.

Moore TH, Zammit S, Lingford-Hughes A, Barnes TR, Jones PB, Burke $M$ et al (2007). Cannabis use and risk of psychotic or affective mental health outcomes: a systematic review. Lancet 370: 319-328.

Morrison PD, Zois V, McKeown DA, Lee TD, Holt DW, Powell JF et al (2009). The acute effects of synthetic intravenous Delta9tetrahydrocannabinol on psychosis, mood and cognitive functioning. Psychol Med 39: 1607-1616.

Moy SS, Nadler JJ, Perez A, Barbaro RP, Johns JM, Magnuson TR (2004). Sociability and preference for social novelty in five inbred strains: an approach to assess autistic-like behavior in mice. Genes Brain Behav 3: 287-302.

Murray RM, Morrison PD, Henquet C, Di Forti M (2007). Cannabis, the mind and society: the hash realities. Nat Rev Neurosci 8: 885-895.

O’Shea M, McGregor IS, Mallet PE (2006). Repeated cannabinoid exposure during perinatal, adolescent or early adult ages produces similar long-lasting deficits in object recognition and reduced social interaction in rats. J Psychopharmacol 20: 611-621.

O'Shea M, Singh ME, McGregor IS, Mallet PE (2004). Chronic cannabinoid exposure produces lasting memory impairment and increased anxiety in adolescent but not adult rats. $J$ Psychopharmacol 18: 502-508.

O’Tuathaigh CM, Babovic D, O'Sullivan GJ, Clifford JJ, Tighe O, Croke DT et al (2007). Phenotypic characterization of spatial cognition and social behavior in mice with 'knockout' of the schizophrenia risk gene neuregulin 1. Neuroscience 147: $18-27$.

O’Tuathaigh CMP, Tighe O, Harte M, O'Leary C, O'Sullivan GJ, Blau C et al (2010). Schizophrenia-related endophenotypes in heterozygous neuregulin-1 'knockout' mice. Eur J Neurosci 31: 349-358.

Papaleo F, Crawley JN, Song J, Lipska BK, Pickel J, Weinberger DR et al (2008). Genetic dissection of the role of catechol-Omethyltransferase in cognition and stress reactivity in mice. J Neurosci 28: 8709-8723.

Patton GC, Coffey C, Carlin JB, Degenhardt L, Lynskey M, Hall W (2002). Cannabis use and mental health in young people: cohort study. BMJ 325: 1195-1198.

Pellow S, File SE (1986). Anxiolytic and anxiogenic drug effects on exploratory activity in an elevated plus-maze: a novel test of anxiety in the rat. Pharmacol Biochem Behav 24: 525-529.

Perry W, Minassian A, Paulus MP, Young JW, Kincaid MJ, Ferguson EJ et al (2009). A reverse-translational study of dysfunctional exploration in psychiatric disorders: from mice to men. Arch Gen Psychiatry 66: 1072-1080.

Pistis M, Porcu G, Melis M, Diana M, Gessa GL (2001). Effects of cannabinoids on prefrontal neuronal responses to ventral tegmental area stimulation. Eur J Neurosci 14: 96-102.

Quinn HR, Matsumoto I, Callaghan PD, Long LE, Arnold JC, Gunasekaran $\mathrm{N}$ et al (2008). Adolescent rats find repeated delta(9)-THC less aversive than adult rats but display greater residual cognitive deficits and changes in hippocampal protein expression following exposure. Neuropsychopharmacology 33: $1113-1126$

Rebec GV (2006). Behavioral electrophysiology of psychostimulants. Neuropsychopharmacology 31: 2341-2348.

Rodriguez de Fonseca F, Ramos JA, Bonnin A, Fernandez-Ruiz JJ (1993). Presence of cannabinoid binding sites in the brain from early postnatal ages. NeuroReport 4: 135-138.

Rubino T, Vigano D, Realini N, Guidali C, Braida D, Capurro V (2008). Chronic D9-tetrahydrocannabinol during adolescence provokes sex-dependent changes in the emotional profile in adult rats: behavioral and biochemical correlates. Neuropsychopharmacology 33: 2760-2771.

Rubino T, Realini N, Braida D, Guidi S, Capurro V, Vigano D et al (2009). Changes in hippocampal morphology and neuroplasticity induced by adolescent THC treatment are associated with cognitive impairment in adulthood. Hippocampus 19: 763-772.

Sankoorikal GK, Kaercher KA, Boon CJ, Lee JK, Brodkin ES (2006). A mouse model system for genetic analysis of sociability: C57BL/6J vs BALB/cJ inbred mouse strains. Biol Psychiatry 59: 415-423.

Schneider M, Koch M (2003). Chronic pubertal, but not adult chronic cannabinoid treatment impairs sensorimotor gating, recognition memory, and the performance in a progressive ratio task in adult rats. Neuropsychopharmacology 28: 1760-1769.

Schramm-Sapyta NL, Cha YM, Chaudhry S, Wilson WA, Swartzwelder HS, Kuhn CM (2007). Differential anxiogenic, aversive, and locomotor effects of THC in adolescent and adult rats. Psychopharmacology 191: 867-877.

Seamans JK, Yang CR (2004). The principal features and mechanisms of dopamine modulation in the prefrontal cortex. Prog Neurobiol 74: 1-58. 
Seeman P (1999). Images in neuroscience. Brain development, X: pruning during development. Am J Psychiatry 156: 168.

Squire LR, Wixted JT, Clark RE (2007). Recognition memory and the medial temporal lobe: a new perspective. Nat Rev Neurosci 8: 872-883.

Stefanis NC, Delespaul P, Henquet C, Bakoula C, Stefanis CN, Van Os J (2004). Early adolescent cannabis exposure and positive and negative dimensions of psychosis. Addiction 99: 1333-1341.

Tarazi FI, Tomasini EC, Baldessarini RJ (1999). Postnatal development of dopamine D1-like receptors in rat cortical and striatolimbic brain regions: an autoradiographic study. Dev Neurosci 21: 43-49.

Teicher MH, Andersen SL, Hostetter Jr JC (1995). Evidence for dopamine receptor pruning between adolescence and adulthood in striatum but not nucleus accumbens. Dev Brain Res 89: 167-172.

Tunbridge EM, Harrison PJ, Weinberger DR (2006). Catechol-omethyltransferase, cognition, and psychosis: Val158Met and beyond. Biol Psychiatry 60: 141-151.
Van den Buuse M (2010). Modelling the positive symptoms of schizophrenia in genetically-modified mice: pharmacology and methodology aspects. Schizophr Bull 36: 246-270.

Viveros MP, Marco EM, File SE (2005a). Endocannabinoid system and stress and anxiety responses. Pharmacol Biochem Behav 81: 331-342.

Viveros MP, Llorente R, Moreno E, Marco EM (2005b). Behavioural and neuroendocrin effects of cannabinoids in critical developmental periods. Behav Pharmacol 16: 353-362.

Wegener N, Koch M (2009). Behavioural disturbances and altered Fos protein expression in adult rats after chronic pubertal cannabinoid treatment. Brain Res 1253: 81-91.

Xie T, Ho SL, Ramsden D (1999). Characterization and implications of estrogenic down-regulation of human catechol-Omethyltransferase gene transcription. Mol Pharmacol 56: 31-38.

Yavich L, Forsberg MM, Karayiorgou M, Gogos JA, Mannisto PT (2007). Site-specific role of catechol-O-methyltransferase in dopamine overflow within prefrontal cortex and dorsal striatum. J Neurosci 27: 10196-10209.

Supplementary Information accompanies the paper on the Neuropsychopharmacology website (http://www.nature.com/npp) 